\title{
Instabilities and robust control in natural resource management
}

\author{
Anastasios Xepapadeas · Catarina Roseta-Palma
}

Received: 26 July 2012 / Accepted: 27 June 2013 / Published online: 1 August 2013 (C) ISEG 2013

\begin{abstract}
Most renewable natural resources exhibit marked demographic and environmental stochasticities, which are exarcebated in management decisions by the uncertainty regarding the choice of an appropriate model to describe system dynamics. Moreover, demand and supply analysis often indicates the presence of instabilities and multiple equilibria, which may lead to management problems that are intensified by uncertainty on the evolution of the resource stock. In this paper the fishery management problem is used as an example to explore the potential of robust optimal control, where the objective is to choose a harvesting rule that will work under a range of admissible specifications for the stock-recruitment equation. The paper derives robust harvesting rules leading to a unique equilibrium, which could be helpful in the design of policy instruments such as robust quota systems.
\end{abstract}

Keywords Natural resource management · Uncertainty · Multiple equilibria · Instabilities $\cdot$ Robust control $\cdot$ Robust harvesting rules

JEL Classifications (2010) Q22 · D81

\footnotetext{
A. Xepapadeas

Athens University of Economics and Business and Beijer Fellow, Athens, Greece

e-mail: xepapad@aueb.gr

C. Roseta-Palma $(\bowtie)$

Department of Economics and Business Research Unit (BRU-IUL),

Instituto Universitario de Lisboa (ISCTE-IUL), Av. Forças Armadas,

1649-026 Lisboa, Portugal

e-mail: catarina.roseta@iscte.pt
} 